\title{
Sensopercepción olfatoria: una revisión
}

\author{
ALER FUENTES ${ }^{1,2, a}$, MARÍA JAVIERA FRESNO ${ }^{1,2, a}$, \\ HUGO SANTANDER $^{2, \mathrm{a}}$, SAÚL VALENZUELA ${ }^{1,2, \mathrm{a}}$, \\ MARIO FELIPE GUTIÉRREZ ${ }^{2, a}$, RODOLFO MIRALLES ${ }^{2, a}$
}

${ }^{1}$ Departamento de Prótesis, Facultad de Odontología, Universidad de Chile, Santiago, Chile.

${ }^{2}$ Laboratorio de Fisiología Oral, Facultad de Medicina, Universidad de Chile, Santiago, Chile. ${ }^{a}$ Cirujano Dentista.

Recibido el 19 de julio de 2010, aceptado el 2 de diciembre de 2010.

Correspondencia a: Dr. Aler Fuentes del Campo Morandé 617 Dpto. 808-A. Fono: 9786420. Santiago, Chile. E-mail: alerfuentes@gmail.

\section{Olfactory sensory perception}

The five senses have had a fundamental importance for survival and socialization of human beings. From an evolutionary point of view the sense of smell is the oldest. This sense has a strong representation within the genome, allowing the existence of many types of receptors that allow us to capture multiple volatile odor producing molecules, sending electrical signals to higher centers to report the outside world. Several cortical areas are activated in the brain, which are interconnected to form an extensive and complex neural network, linking for example, areas involved with memory and emotions, thus giving this sense of perceptual richness. While the concept of flavor is largely related to the sense of taste, smell provides the necessary integration with the rest of the senses and higher functions. Fully understanding the sense of smell is relevant to health professionals. Knowing the characteristics of the receptors, the transduction processes and convergence of information in the higher centers involved, we can properly detect olfactory disorders in our patients.

(Rev Med Chile 2011; 139: 362-367).

Key words: Olfaction disorders; Olfactory perception; Olfactory receptor neurons.

\section{L} os seres humanos poseen una relación de reciprocidad e interdependencia con su entorno, por esto, deben estar preparados para adaptarse a sus continuos cambios. Para lograr captar las señales químicas del ambiente, es de vital importancia el sentido del olfato, ya que nos permite captar las sustancias dispersas en el aire y al percibir estas señales, desarrollar conductas tendientes a lograr la supervivencia, como son el encontrar fuentes de alimento y hábitat, así como conseguir la interacción social y reproducción. En los mamíferos estas señales químicas son recibidas por dos sistemas olfatorios diferentes: el sistema olfatorio principal y el sistema olfatorio accesorio o vomeronasal ${ }^{1}$. Desde un punto de vista convencional, el sistema olfatorio principal es el responsable de la detección de odorantes volátiles comunes, y el sistema olfatorio accesorio responde a las feromonas involucradas en la comunicación social ${ }^{2}$.

El objetivo de la presente revisión es describir en forma detallada el sistema olfatorio principal y mencionar algunos aspectos del sistema olfato- rio accesorio, que pueden ser de gran utilidad al clínico en su práctica diaria.

\section{Sistema olfatorio principal}

El olfato es el sentido corporal que distingue diferentes sustancias dispersas en el aire. También se define como la capacidad para detectar odorantes, como es la función de las neuronas olfatorias receptoras. Cabe destacar la diferencia con la percepción olfatoria que es el proceso por el cual los estímulos olfatorios en su naturaleza y significado, son reconocidos e interpretados por el cerebro, gracias a lo cual podemos diferenciar, entre otros, el concepto de aroma de lo que se refiere a hedor.

El sentido del olfato es el único sistema que posee una modalidad "dual", es decir, detecta los estímulos provenientes del mundo exterior y del interior del cuerpo, como se explicará más adelante ${ }^{3}$. 


\section{Neuroepitelio olfatorio}

En los humanos, el neuroepitelio olfatorio se encuentra ubicado en la parte superior de cada fosa nasal, pigmentado de color amarillento $y$ cubre un área aproximada de $2 \mathrm{~cm}^{2}$ en cada una, sin embargo, esta no se considera una estructura homogénea, al menos en los adultos, ya que existen variaciones en su extensión dependiendo de los autores ${ }^{4-5}$. El pequeño tamaño de este epitelio se puede deber a la historia evolutiva del Homo sapiens, el cual en sus comienzos presentaba una alta homogeneidad genética lo que dificultaba su reproducción, por lo cual se adaptó disminuyendo su magnitud, favoreciendo la endogamia y por lo tanto la descendencia ${ }^{6}$.

El área donde se encuentra localizado está pobremente ventilada debido a que la mayoría del aire inspirado pasa a través de la zona baja de la cavidad nasal, siendo desviado hacia el neuroepitelio olfatorio sólo entre 10 y $15 \%$ de éste ${ }^{4}$. El neuroepitelio presenta un reemplazo constante de sus células, cuyas neuronas olfatorias poseen un rango de vida de entre 30 a 120 días $^{7}$.

El neuroepitelio olfatorio consta de dos capas: la mucosa olfatoria y la lámina propia ${ }^{5}$. En base al criterio anatómico e inmunohistoquímico, al menos 6 clases de células principales pueden ser identificadas ${ }^{8}:$ neuronas sensoriales ciliadas bipolares, células de soporte, células con microvellosidades, células basales globosas, células basales horizontales y células de los ductos de las glándulas submucosas o de Bowman.

Las neuronas sensoriales olfatorias dirigen una única dendrita a la superficie del neuroepitelio olfatorio, la cual posee una terminación engrosada llamada vesícula olfatoria, que proyecta cilios inmóviles, donde se encuentran los receptores olfatorios.

Las células de soporte se encuentran rodeando las neuronas sensoriales olfatorias, regulando y manteniendo el medio iónico apropiado para que la transducción de la señal ocurra y junto con el mucus contribuyen en la remoción de moléculas odorantes y de sustancias tóxicas 5 .

La función de las llamadas células con microvellosidades, ubicadas en la superficie epitelial, aún es desconocida ${ }^{4}$.

Las células basales horizontales y globosas son las progenitoras del epitelio olfatorio, participando en el recambio celular normal y pueden permitir la regeneración de componentes dañados ${ }^{5}$. Las células basales horizontales se encuentran directamente unidas a la lámina basal y son las precursoras directas de casi todos los tipos celulares del neuroepitelio olfatorio, excepto las neuronas, de donde son precursores indirectos, ya que diferencian a células basales globosas y estas a su vez en neuronas olfatorias .

Las glándulas submucosas son la principal fuente de mucus de la región olfatoria, el cual baña los cilios neuronales, brinda protección antimicrobiana de la vía aérea alta y proporciona un medio molecular y iónico adecuado para la detección de odorantes. Además, las células de sus ductos expresan aquoporinas y canales iónicos, lo que contribuye al flujo de agua e iones dentro del lumen ductal ${ }^{10}$.

El mucus nasal posee proteínas olfatorias ligando (OBP), las que protegen el epitelio del daño causado por el estrés oxidativo, removiendo los componentes citotóxicos del mucus nasal. También poseen funciones olfatorias, entre las cuales se encuentran: ser transportadoras de moléculas volátiles y ligandos hidrofóbicos a través de la capa acuosa de mucus hacia el receptor, unir varias moléculas odorantes, juegan un rol en el reconocimiento del complejo ligando-OBP con el receptor neuronal, contribuir a amplificar la señal olfatoria y participar en la remoción de los odorantes en el receptor para el cese de las señales olfatorias ${ }^{11,12}$.

\section{Receptores olfatorios}

El descubrimiento de Buck y Axel en 1991 acerca de la familia de receptores olfatorios en roedores, fue un hito en el entendimiento de la función olfatoria, cambiando el rumbo de las investigaciones futuras ${ }^{13}$. Hoy sabemos que las moléculas odorantes para ser reconocidas por los receptores se deben encontrar en un rango entre los 200 y 400 dalton, describiéndose un número aproximado de 10.000 ligandos olorosos, sin embargo, la cantidad de moléculas que se encuentran entre esos tamaños de masa atómica es infinita ${ }^{14,15}$.

Los seres humanos poseen aproximadamente 900 genes para receptores olfatorios, es decir un $3 \%$ del genoma, de los cuales $63 \%$ son no codificantes, por lo cual son llamados pseudo-genes ${ }^{16}$. Cada gen funcional codifica un tipo de receptor, permitiendo la existencia de 300 receptores di- 
ferentes y cada neurona olfatoria expresa sólo un gen, por lo tanto, un solo tipo de receptor, encontrándose distribuidas al azar en el epitelio olfatorio ${ }^{17}$. Sin embargo, cada neurona olfatoria puede reconocer múltiples odorantes.

Todos los receptores de olfato son miembros de la superfamilia de receptores acoplados a proteína $\mathrm{G}^{18}$.

\section{Transducción de las señales olfatorias}

Una vez que el ligando oloroso se ha unido a el receptor olfatorio, se activa la proteína $G$ (un subtipo especifico llamado $G_{\text {olf }}$ ), la que a su vez acciona la adenilil ciclasa III (ACIII). Esta ACIII convierte las abundantes moléculas intracelulares de ATP en AMP cíclico (AMPc) y este AMPc se une a la superficie intracelular de un canal iónico denominado compuerta de nucleótidos cíclicos (CNG). Cuando el canal CNG se abre, el influjo de los iones $\mathrm{Na}^{+}$y $\mathrm{Ca}^{2+}$ causan que al interior de la membrana celular se torne menos negativo, generando un potencial de acción ${ }^{18}$.

La cascada de segundos mensajeros y enzimas provee amplificación y adaptación a los eventos olorosos. En el caso de la amplificación, los iones de $\mathrm{Ca}^{2+}$ que entran a través del canal CNG están capacitados para activar el canal iónico de $\mathrm{Cl}^{-}$, los cuales normalmente median respuestas inhibitorias; sin embargo, la salida de $\mathrm{Cl}^{-}$mantiene la despolarización de la membrana, aumentando la magnitud de la respuesta excitatoria ${ }^{18}$. Esta respuesta inicial de la neurona sensorial al estimulo odorante es seguida por un período de adaptación, esta acción inhibitoria es producida por el complejo $\mathrm{Ca}^{2+}$-calmodulina, debido a que éste provoca una retroalimentación negativa, reduciendo la afinidad del canal CNG por AMPc y además aumenta la actividad de la fosfodiesterasa que hidroliza el AMPc ${ }^{14,18}$.

\section{Bulbos olfatorios y células mitrales}

Los axones de las neuronas sensoriales dejan el epitelio olfatorio y atraviesan la base del cráneo a través de múltiples aberturas de la lámina cribiforme para entrar en el bulbo olfatorio. Estos axones se agrupan en estructuras esféricas en la capa superficial del bulbo olfatorio, llamados glomérulos ${ }^{15}$. Cada bulbo olfatorio se encuentra topográficamente organizado, con glomérulos individuales que representan un único tipo de receptor, encontrándose correspondencia entre el número de genes y el de glomérulos. Se ha demostrado que los axones de las neuronas que expresan el mismo receptor de odorante convergen con extraordinaria precisión en su glomérulo específico, pudiendo proyectar además a pocos glomérulos vecinos ${ }^{19}$. Este concepto de convergencia es consistente con lo ampliamente aceptado sobre codificación olfatoria, en la cual una combinación particular de glomérulos activados, establece una representación espacial informando al cerebro sobre lo que se está olfateando ${ }^{14}$. Se generan así los "mapas de olor", considerando los glomérulos olfatorios como módulos estructurales y funcionales que se extienden en las profundidades de los bulbos olfatorios ${ }^{20}$.

En los glomérulos olfatorios se produce la sinapsis con las dendritas de las células mitrales y en penacho, las cuales también poseen convergencia en su información, ya que cada una de ellas recibe estimulación de un único glomérulo ${ }^{21}$. Estas neuronas de segundo orden, a su vez, envían colaterales que sinaptan con numerosos tipos de interneuronas como son las periglomerulares y granulosas, cuya función es formar circuitos reverberantes de retroalimentación negativa y positiva; de hecho las células mitrales modulan su propia labor, mediante la activación de las células granulosas, que le son inhibitorias ${ }^{4,14}$.

\section{Vía olfatoria}

Los axones de las células mitrales y en penacho de cada bulbo se unen para formar el tracto olfatorio, uno a cada lado. Esta estructura lleva la información de manera ipsilateral a un amplio número de áreas cerebrales dentro de la superficie orbital posterior del lóbulo frontal y la superficie dorsomedial del lóbulo temporal22.

Se define como corteza olfatoria primaria a todas las regiones cerebrales que reciben información directa desde los bulbos olfatorios. Estas estructuras incluyen la corteza piriforme, el tubérculo olfatorio, el núcleo olfatorio anterior, el complejo amigdalino y la corteza entorrinal ${ }^{22,23}$. Proyecciones procedentes desde estructuras primarias convergen en las regiones denominadas 
corteza olfatoria secundaria, que comprende la corteza orbitofrontal, el subnúcleo adicional de la amígdala, el hipotálamo, la ínsula, el tálamo dorsomedial y el hipocampo 22 .

La corteza piriforme aparece involucrada en la memoria y reconocimiento de los olores. La corteza entorrinal juega un rol en la codificación de la intensidad del odorante ${ }^{24}$. El hipocampo y amígdala son activados durante la discriminación, identificación y memoria ${ }^{15,23}$. La corteza orbitofrontal es el principal receptor de las proyecciones olfatorias vía directa desde la corteza olfatoria primaria, y vía indirecta desde el núcleo dorsomedial del tálamo ${ }^{23}$. Esta estructura participa en la percepción y significancia hedónica del olor ${ }^{25}$. La ínsula está relacionada con el sistema límbico ${ }^{15}$.

Es importante destacar que la función olfatoria involucra una compleja y extensa red neuronal, por lo que las funciones antes descritas no son exclusivas de cada estructura sino del conjunto. Además, la información olfatoria aparece basada en dos principales maneras de procesamiento, un procesamiento serial con la participación sucesiva de las áreas olfatorias primaria y secundaria, y un procesamiento paralelo (hemisferio derecho versus hemisferio izquierdo) donde las estructuras en el hemisferio derecho se encuentran más involucradas en la memoria, mientras que las del hemisferio izquierdo, en los procesos emocionales ${ }^{26}$.

\section{Sistema del sabor}

No sólo es primordial saber qué regiones del cerebro se encuentran involucradas en el fenómeno de la olfacción, sino además como la respuesta del cerebro puede variar de acuerdo a la fuente odorífera $^{23}$. Específicamente, los odorantes pueden ser percibidos a través de la nariz, lo que es conocido como olfato ortonasal; y a través de la boca, llamado olfato retronasal ${ }^{27}$. A este respecto, el sentido del olfato es el único sistema que posee una modalidad "dual”, es decir, detecta los estímulos provenientes del mundo exterior y del interior del cuerpo ${ }^{3}$.

La estimulación ortonasal se refiere a la olfacción a través de las narinas externas que activan las células sensoriales del epitelio olfatorio. La estimulación retronasal ocurre durante la ingestión de alimentos, cuando las moléculas volátiles liberadas son empujadas por movimientos de la boca desde la zona posterior de la cavidad bucal a través de la nasofaringe hacia el epitelio olfatorio, lo cual ocurre en la espiración a través de la nariz entre masticaciones o degluciones. El olfato ortonasal no contribuye a esta sensación porque las moléculas que surgen del alimento en la boca son referidas a la boca, es decir, ellas son percibidas como si fueran detectadas dentro de la boca $^{28,29}$. Este aire cargado con moléculas de los alimentos es considerado como parte del "gusto" de las comidas y ha demostrado ser necesario en la identificación del sabor. Para evitar que el término "gusto" posea un doble significado, se ha incorporado el concepto de olfato retronasal como una de las modalidades cubiertas por el termino "sabor". Para que este fenómeno suceda deben integrase muchas modalidades, como el gusto, la visión, el tacto, la audición, la propiocepción, la deglución, la respiración, los sistemas cognitivos, la memoria, la emoción, el pensamiento abstracto y el lenguaje, entre otros ${ }^{28}$. La estimulación conjunta del gusto y olfato retronasal produce un aumento de la actividad en muchas de las regiones activadas por los estímulos independientes, así como actividad adicional en áreas contiguas alrededor de la áreas receptoras primarias, lo que conlleva a una actividad integradora más compleja de percepción del sabor que sólo por la simple adición de las vías gustatorias y olfativas, fenómeno conocido como "integración neocortical"30.

\section{Alteraciones olfatorias}

Son provocadas por una variedad de razones que pueden influenciar profundamente la calidad de vida de las personas y se pueden clasificar de la siguiente manera ${ }^{20}$ :

Anosmia: imposibilidad para detectar cualitativamente las sensaciones olfatorias, es decir ausencia de función olfatoria (anosmia total), o habilidad para percibir sólo algunos odorantes (anosmia parcial). Puede ser provocada entre otras por un traumatismo craneal, daño permanente en el neuroepitelio olfatorio, infecciones respiratorias o tener un origen congénito ${ }^{31}$.

Hiposmia o microsmia: sensibilidad disminuida para la detección de odorantes. Sus posibles causas son enfermedad nasal o paranasal, terapia con radiación y exposición a toxinas como el humo del cigarrillo, entre otras. Se ha demostrado que un aumento en la edad sobre los 65 años también provoca esta condición ${ }^{32}$. 
Hiperosmia: agudeza anormal de la función olfatoria (aumento de su sensibilidad). Aunque es rara, se podría encontrar en pacientes con insuficiencia adrenal cortical y epilepsia ${ }^{33}$.

Disosmia o parosmia (cacosmia): percepción olfatoria distorsionada. Se puede observar en casos de sinusitis, tumores cerebrales, desórdenes neurológicos y siquiátricos ${ }^{4}$.

Fantosmia: sensación olfatoria percibida en ausencia de un estímulo oloroso, también llamadas alucinaciones olfatorias. Puede deberse a lesiones cerebrales centrales y epilepsia ${ }^{34}$.

Agnosia olfatoria: imposibilidad de reconocer una sensación odorífera, a pesar que el procesamiento olfatorio, lenguaje y funciones intelectuales generales se encuentren esencialmente intactos. Esta condición se puede encontrar en pacientes con esquizofrenia ${ }^{15}$.

\section{Sistema olfatorio accesorio}

Hace poco más de cincuenta años, Peter Karlson y Martin Lüscher propusieron una nueva palabra para definir a un grupo de sustancias químicas utilizadas en la comunicación entre los individuos de la misma especie; las llamaron feromonas ${ }^{35}$. Estas señales químicas proporcionan información acerca del género, dominancia y estado reproductivo, las cuales son detectadas por una estructura tubular elongada llamada órgano vomeronasal (OVN), localizada en la cavidad nasal y tapizada por neuronas sensoriales ${ }^{36,37}$.

Algunos investigadores señalan que el OVN no existe en los seres humanos, por lo que esta teoría podría excluirnos de responder a las señales de las feromonas ${ }^{38}$. Otros en cambio expresan que el ser humano podría no necesitar el OVN para recibir esta información, ya que ambos sistemas olfatorios se encuentran integrados en el cerebro, haciendo que el OVN no fuese necesario ${ }^{39}$. Como vemos, aún no existe consenso al respecto, sin embargo, Wyatt comenta que está seguro que las feromonas humanas aún nos pueden sorprender ${ }^{40}$.

\section{Referencias}

1. Breer H, Fleischer J, Strotmann J. The sense of smell: Multiple olfactory subsystems. Cell Mol Life Sci 2006; 63: 1465-75.

2. Kang N, Baum MJ, Cherry JA. A direct main olfactory bulb projection to the "vomeronasal" amygdala in female mice selectively responds to volatile pheromones from males. Eur J Neurosci 2009; 29: 624-34.

3. Rozin P. "Taste-smell confusions" and the duality of the olfactory sense. Percept Psychophys 1982; 31: 397-401.

4. Doty L, Bromley SM. Olfaction and Gustation. En: Snow J, Ballenger J. Ballenger's Otorhinolaryngology: Head and Neck Surgery. Hamilton, Ontario, Canadá: Editorial BC Decker 16a edición; 2003. p. 561-91.

5. Hadley K, Orlandi RR, Fong KJ. Basic anatomy and physiology of olfaction and taste. Otolaryngol Clin North Am 2004; 37: 1115-26.

6. Lee RV. [Nausea and vomiting of pregnancy: An evolutionary hypothesis]. Rev Med Chile 2002; 130: 580-4.

7. Astic L, Saucier D. Neuronal plasticity and regeneration in the olfactory system of mammals: morphological and functional recovery following olfactory bulb deafferentation. Cell Mol Life Sci 2001; 58: 538-45.

8. Huard JM, Youngentob SL, Goldstein BL, Luskin MB, Schwob JE. Adult olfactory epithelium contains multipotent progenitors that give rise to neurons and nonneural cells. J Comp Neurol 1998; 400: 469-86.

9. Iwai N, Zhou Z, Roop DR, Behringer RR. Horizontal basal cells are multipotent progenitors in normal and injured adult olfactory epithelium. Stem Cells 2008; 26: 1298-306.

10. Baraniuk J, Merck S. New concepts of neural regulation in human nasal mucosa. Acta Clin Croat 2009; 48: 65-73.

11. Hajjar E, Perahia D, Débat H, Nespoulous C, Robert CH. Odorant binding and conformational dynamics in the odorant-binding protein. JBC 2006; 6: 281: 29929-37.

12. Stopková R, Zdráhal Z, Ryba S, Sedo O, Sandera M, Stopka P. Novel OBP genes similar to hamster Aphrodisin in the bank vole, Myodes glareolus. BMC Genomics 2010; 11: 45, 1-10.

13. Buck L, Axel R. A novel multigene family may encode odorant receptors: a molecular basis for odor recognition. Cell 1991; 65: 175-87.

14. Menini A, Lagostena L, Boccaccio A. Olfaction: from odorant molecules to the olfactory cortex. News Physiol Sci 2004; 19: 101-4.

15. Kivity S, Ortega-Hernández OD, Shoenfeld Y. Olfactiona window to the mind. Isr Med Assoc J 2009; 11: 238-43.

16. Glusman G, Yanai I, Rubin I, Lancet D. The complete human olfactory subgenome. Genome Res 2001; 11: 685-702.

17. Spehr M, Munger SD. Olfactory receptors: G proteincoupled receptors and beyond. J Neurochem 2009; 109: 1570-83.

18. Firestein S. How the olfactory system makes sense of scents. Nature 2001; 413: 211-8. 
19. Mombaerts P. How smell develops. Nat Neurosci 2001; 4: 1192-8.

20. Kratskin IL, Belluzzi O. Anatomy and Neurochemistry of the Olfactory Bulb. Murphy C, Doty R, Duncan H. Clinical Disorders of Olfaction. En: Doty R. Handbook of Olfaction and Gustation. Nueva York, Estados Unidos: Editorial Marcel Dekker 2a edición; 2003.

21. Tran H, Chen H, Walz A, Posthumus JC, Gong Q. Influence of olfactory epithelium on mitral/tufted cell dendritic outgrowth. PLoS One 2008; 3: e3816 1-8.

22. Gottfried JA, Small DM, Zald DH. The chemical senses. En: Zald DH, Rauch S. The Orbitofrontal Cortex. Oxford, Reino Unido: Editorial Oxford University Press $1^{\text {a }}$ edición; 2006. p. 125-71.

23. Zelano C, Sobel N. Humans as an animal model for systems-level organization of olfaction. Neuron 2005; 48: 431-54.

24. Rolls ET, Kringelbach ML, de Araujo IE. Different representations of pleasant and unpleasant odours in the human brain. Eur J Neurosci 2003; 18: 695-703.

25. Kringelbach ML. The human orbitofrontal cortex: linking reward to hedonic experience. Nat Rev Neurosci 2005; 6: 691-702.

26. Royet JP, Plailly J. Lateralization of olfactory processes. Chem Senses 2004; 29: 731-45.

27. Murphy C, Cain WS, Bartoshuk LM. Mutual action of taste and olfaction. Sens Processes 1977; 1: 204-11.

28. Shepherd GM. Smell images and the flavour system in the human brain. Nature 2006; 444 (7117): 316-21.

29. Bartoshuk LM, Duffy BV, Chapo KA, Fast K, Yiee HJ, Hoffman JH, et al. From psychophysics to the clinic: missteps and advances. Food Qual Preference 2004; 15: 617-32.
30. Small DM, Gerber JC, Mak YE, Hummel T. Differential neural responses evoked by orthonasal versus retronasal odorant perception in humans. Neuron 2005; 47: 593605.

31. Yousem DM, Geckle RJ, Bilker W, McKeown DA, Doty RL. MR evaluation of patients with congenital hyposmia or anosmia. Am J Roentgenol 1996; 166: 439-43.

32. Doty RL, Shaman P, Applebaum SL, Giberson R, Siksorski L, Rosenberg L. Smell identification ability: changes with age. Science 1984; 226: 1441-3.

33. Doty RL, Risser JM. Brosvic GM. Influence of adrenalectomy on the odor detection performance of rats. Physiol Behav 1991; 49: 1273-7.

34. West SE, Doty RL. Influence of epilepsy and temporal lobe resection on olfactory function. Epilepsia 1995; 36: 531-42.

35. Karlson P, Lüscher M. "Pheromones": A new term for a class of biologically active substances. Nature 1959; 183: 55-6.

36. Meredith M. Human Vomeronasal Organ Function: A Critical Review of Best and Worst Cases. Chem Senses 2001; 26: 433-45.

37. Halpern M, Martínez-Marcos A. Structure and function of the vomeronasal system: an update. Prog Neurobiol 2003; 70: 245-318.

38. Witt M, Wo niak W. Structure and function of the vomeronasal organ. Adv Otorhinolaryngol 2006; 63: 70-83.

39. Liberles SD, Buck LB. A second class of chemosensory receptors in the olfactory epithelium. Nature 2006; 442 (7103): 645-50.

40. Wyatt TD. Fifty years of pheromones. Nature 2009; 457 (7227): 262-3. 